\title{
Morphometrics of foramen magnum in African four-toed hedgehog (Atelerix albiventris)
}

\author{
I. Girgiri ${ }^{1}$, J.O. Olopade ${ }^{2}$, A. Yahaya ${ }^{1}$ \\ ${ }^{1}$ Department of Veterinary Anatomy, Faculty of Veterinary Medicine, University of Maiduguri, Nigeria \\ 2Department of Veterinary Anatomy, Faculty of Veterinary Medicine, University of Ibadan, Nigeria
}

[Received 17 January 2014; Accepted 27 February 2014]

\begin{abstract}
The purpose of this study was to examine the morphometry of the foramen magnum of African four-toed hedgehog (Atelerix albiventris) in Maiduguri. Fourteen hedgehog skulls (7 male and 7 female each) were used for this study. The overall mean value of foramen magnum height and width were $0.51 \pm 0.05 \mathrm{~cm}$ and $0.64 \pm 0.04 \mathrm{~cm}$ while occipital condylar and interparacondylar widths were $1.00 \pm 0.12 \mathrm{~cm}$ and $1.62 \pm 0.07 \mathrm{~cm}$, respectively. There was no significant difference between the two sexes. The foramen magnum index was $83.4 \pm 5.51 \mathrm{~cm}$ in males and was significantly higher than $76.3 \pm 6.37 \mathrm{~cm}$ observed in females. The presences of dorsal notches (occipital dysplasia) were observed, that were of three distinct types. It is envisaged, that the study will provide a valuable database on the anatomy of foramen magnum of hedgehogs in Nigeria for morphologi$\mathrm{cal}$, neurological, zooarchaeological, and comparative anatomical studies. (Folia Morphol 2015; 74, 2: 188-191)
\end{abstract}

Key words: morphometry, foramen magnum, African hedgehog

\section{INTRODUCTION}

The foramen magnum (FM) is a large opening at the base of the skull [6], providing exits for vital structures from the skull to the vertebral column [26]. It is laterally bordered by the occipital condyles [17], and is of variable shapes and forms [1]. FM serves as an important landmark for studies on skull and cranial evolutionary modifications [21], as sex determinants in forensic analysis [7], plays a role in determining ancestry of individuals [5] and has clinical implication in diverse fields of medicine [9]. Irregularities of the dimensions of FM and occipital bone are linked in human and animal to different neurological conditions [11]. Occipital hypoplasia or Chiari-like syndrome has been reported in some breeds of dogs $[18,23]$, equivalent to Arnold Chiari malformation in human [29], predisposing to syringomyelia, due to obstruction of cerebrospinal fluid through the FM [22]. Occipital dysplasia (dorsal notch) [11], concurrent with occipital hypoplasia were also reported in literature $[4,22]$. However, the clinical role of occipital dysplasia is considered controversial [3]. There have been few reported studies with respect to FM in small mammals $[2,15,27]$. Basic information on metrical values and morphology of the FM in African hedgehogs has scarcely been reported in literatures. The goal of the present study is to document a database for the morphometry of FM in four-toed African hedgehog (Atelerix albiventris) found around Maiduguri, North East Nigeria.

\section{MATERIALS AND METHODS}

A total of 14 adult hedgehog heads comprising 7 males and 7 females, were used for this study.

Address for correspondence: Prof. J.O. Olopade, Department of Veterinary Anatomy, Faculty of Veterinary Medicine, University of Ibadan, Nigeria, tel: +23408023860829, e-mail: jkayodeolopade@yahoo.com 


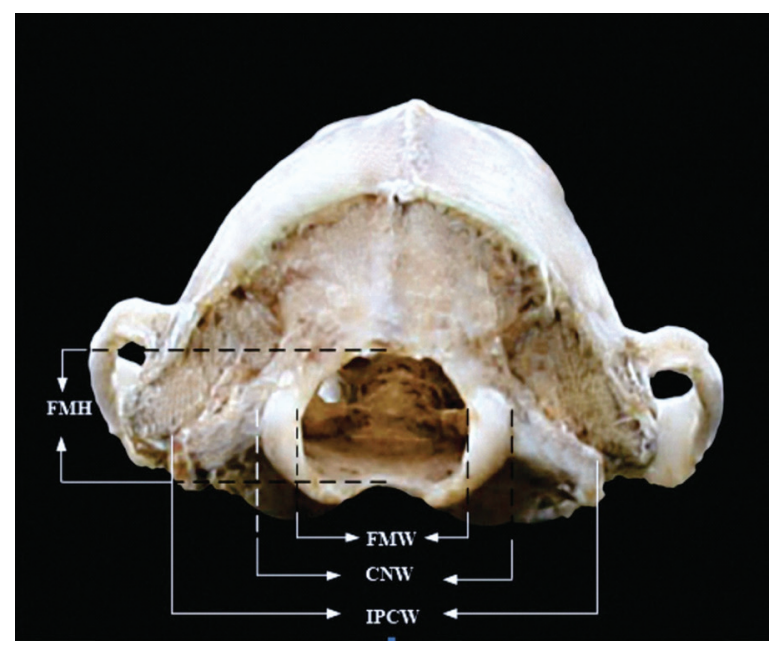

Figure 1. Caudal view of hedgehog skull showing foramen magnum height (FMH), foramen magnum width (FMW), occipital condylar width (OCW), interparacondylar width (IPCW).

The collected hedgehogs were hand-caught by local poachers/farmers around Maiduguri as described by Mouhoub-sayah et al. [13]. The heads were processed by hot water maceration technique in accordance with method described by Onar et al. [16] and Olude et al. [15]. The length and width of the foramen magnum and FM index were obtained as described by Olude et al. [15] and Yahaya et al. [31]. Landmarks of adjacent occipital bones were also determined using a manual Vernier calliper. The description of the indices measured is stated below and most are depicted in Figure 1.

\section{Landmarks}

— Foramen magnum height (FMH): Widest part of the foramen magnum in vertical plane.

- Foramen magnum width (FMW): Widest part of the foramen magnum in a horizontal plane.

- Foramen magnum index (FMI):

$$
\frac{\text { Foramen magnum height }}{\text { Foramen magnum width }} \times 100
$$

- Interparacondylar widths (IPCW): Greatest breadth of the ventromedial end of the jugular process.

- Occipital condylar widths (OCW): Width between the lateral ends of occipital condyles perpendicular to skull axis.

The data obtained were presented as means \pm standard deviation and were analysed using statistical analysis package (GraphPad Instat ${ }^{\circledR}$ version 3.05); analysis for sex comparison was made using Student's t-test with level of significance set at $5 \%$ $(p<0.05)$. Photographs of FM of each skull with different morphology were taken using a canon EOS 5D camera.

\section{RESULTS}

The morphological data of the foramen magnum obtained for male and female hedgehogs are presented in Table 1. Occurrences of variation in shape of the foramen magnum by the presences of dorsal arches at the mid-dorsal margin of the foramen were observed and 3 distinct patterns were distinguished: in the first type, the dorsal margin forms a semi-circular mass that extends ventrally from the dorsal margin of the foramen (Fig. 2A), in the second type, the dorsal margin is indented by a median dorsal notch that extends dorsally (Fig. 2B) while in the third pattern, the dorsal margin of the foramen is smoothly curved devoid of bony protrusion or notch (Fig. 2C).

\section{DISCUSSION}

The mean foramen magnum height and width of hedgehog in this study was $0.51 \pm 0.05 \mathrm{~cm}$ and $0.64 \pm 0.04 \mathrm{~cm}$, respectively (Table 1 ). However, the mean values for the FM height and width for males was $0.54 \pm 0.04 \mathrm{~cm}$ and $0.64 \pm 0.03 \mathrm{~cm}$ while for females was $0.49 \pm 0.06$ and $0.64 \pm 0.04 \mathrm{~cm}$, respectively (Table 1). These were considered not significant. In contrast, Olude et al. [15] observed significantly higher values in FMW of male African giant rat, whereas in Pekingese dogs significant gender

Table 1. Morphometric indices of the foramen magnum and occipital indices of African hedgehog

\begin{tabular}{lccc}
\hline${\text { Parameter }[\mathbf{c m}]^{\#}}^{\#}$ & Overall mean & Male & Female \\
\hline Foramen magnum height (FMH) & $0.51 \pm 0.05$ & $0.54 \pm 0.04$ & $0.49 \pm 0.06$ \\
Foramen magnum width (FMW) & $0.64 \pm 0.04$ & $0.64 \pm 0.03$ & $0.64 \pm 0.04$ \\
Foramen magnum index (FMI) & $79.8 \pm 5.94$ & $83.4 \pm 5.51^{*}$ & $76.3 \pm 6.37$ \\
Occipital condylar width (OCW) & $1.00 \pm 0.12$ & $1.00 \pm 0.18$ & $1.00 \pm 0.06$ \\
Interparacondylar width (IPCW) & $1.62 \pm 0.07$ & $1.64 \pm 0.09$ & $1.61 \pm 0.06$ \\
\hline
\end{tabular}

\#All values are in cm except foramen magnum index which is an index; ${ }^{*}$ Significant differences between means at the significant level of $p<0.05$. 

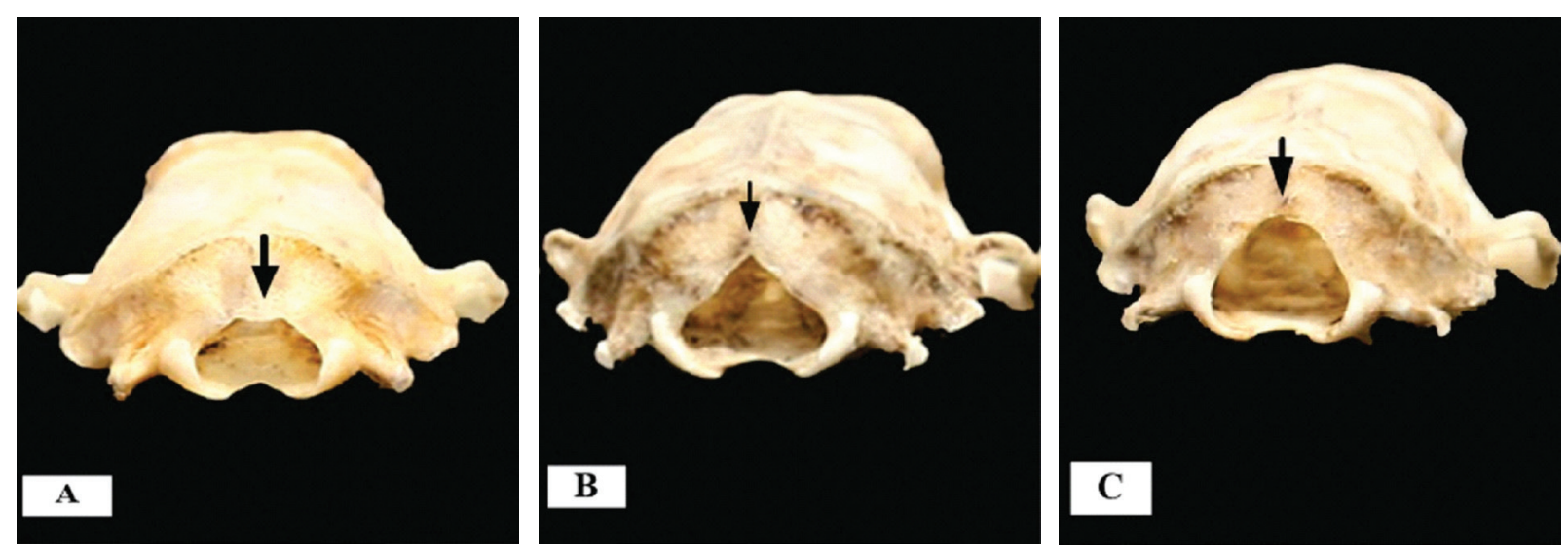

Figure 2. A, B, C. Caudal view of the skull of hedgehog (A. albiventris) skull showing morphological variations in shape of the mid-dorsal margin of foramen magnum.

difference was observed in FMH [24]. In this study the mean FMI in males was observed to be significantly higher than in females and this was due to higher foramen magnum heights in the latter. The mean FMI of $79.8 \pm 5.94$ in hedgehogs was below 100 , corresponding to studies of Olude et al. [15] in African giant rat, Kahvecioglu et al. [12] in rabbit and Simoens et al. [24] in Pekingese dogs but contrary to observations in adult humans [25], camel [31], West African dwarf goat [14] and dog [10], which were above 100 . The mean values of occipital condyle and interparacondylar width reveals no significant difference between the two sexes. However Yahaya et al. [31] reported a significantly larger interparacondylar width in male camels.

In this study, the presence of dorsal notch (Occipital dysplasia) was observed, and was of three distinct types (Fig. 2A-C). Similar findings were reported in African giant rat [15], camels [31] and some breed of dogs $[18,22,23]$. This is seen as a defect in dogs, arising from incomplete ossification of the ventromedial part of the supraoccipital bones [28], and resulting in widening of the FM. The malformation of the FM and occipital bone in relation to their clinical implication, are commonly investigated in different breeds of dogs $[3,23,28]$. However, the clinical role of occipital dysplasia in particular, is debatable. Grimm [8] and Janeczek et al. [10] considered dorsal notch as an ancient feature, which is compatible with longevity. Whereas Watson et al. [28] stated that the dorsal notch is a morphological distinction, arisen from differences in supraoccipital bone ossification. In some breeds of dogs, occipital dysplasia has been reported with either asymptomatic [30], or associated neurological symptoms [20]. In our study, no neurological symptoms were observed. This agrees to finding of Janeczek et al. [11], and Watson et al. [28]. In contrast, our findings differ with the view of Watson et al [28]; that the prospect of dorsal notch incidence is low in dolicocephalic skull to which hedgehog belongs.

\section{CONCLUSIONS}

In conclusion, there is a need for further research to explore the possibilities of relating occipital dysplasia to wobbly hedgehog syndrome, a common neurological disease of uncertain aetiology in hedgehogs [19]. The morphometric data of the FM across the sexes of African four-toed hedgehog (A. albiventris) and the findings obtained from the study will form a good baseline data for further research, and may find application in the field of morphology, zooarchaeology, neurology, and comparative anatomy.

\section{ACKNOWLEDGEMENTS}

The authors gratefully acknowledge the technical assistance of Dr M.M Bukar.

\section{REFERENCES}

1. Avci E, Dagtekin E, Ozturk H, Kara E, Ozturk NC, Uluc K, Akture E, Baskaya MK (2011) Anatomical variation of the foramen magnum, occipital condyle and jugular tubercle. Turk Neurosurg, 21: 181-190.

2. Baranowski P, Wroblewska M, Wojtas J (2009) Morphology and morphometry of the nuchal plane of breeding Chinchilla (Chinchilla laniger, Molina, 1782) skull allowing for sex and litter size at birth. Bull Vet Inst Pulawy, 53: 291-298.

3. Baroni CO, Pinto ACB, Matera JM, Chamone KMC, Hayashi AM (2011) Morphology and morphometry of the foramen 
magnum in toy poodle and yorkshire terrier dogs. Cience Rural Santa Maria, 41: 1239-1244.

4. Cagle L (2010) Concurrent occipital hypoplasia, occipital dysplasia, syringohydromyelia, and hydrocephalus in a yorkshire terrier. CVJ, 51: 904-908.

5. Chethan P, Prakash KG, Murlimanju BV, Prashanth KU, Prabhu LV, Saralaya VV, Krishnamurthy A, Somesh MS, Kumar CG (2011) Morphological analysis and morphometry of the foramen magnum: an anatomical investigation. Turk Neurosurg, 22: 416-419.

6. Dyce KM, Sack WO, Wensing CJG (2010) Textbook of veterinary anatomy. W.B Saunders Coperation, Elsevier, Philadelphia.

7. Gapert R, Black S, Last J (2009) Sex determination from the foramen magnum: discriminant function analysis in an eighteenth and nineteenth century British sample. Int J Legal Med, 123: 25-33.

8. Grimm JM (2010) Occipital dysplasia in dogs: the archaeological evidence. International Council for Archaeozoology Animal Paleopathology Working Group: Animal Disease in Past Human Societies, Greece.

9. Grubber P, Henneberg M, Boni T, Ruhli FJ (2009) Variability of human foramen magnum size. Anat Rec, 292: 1713-1719.

10. Janeczek M, Chroszcz A, Onar V, Pazvant G, Pospieszny N (2008) Morphological analysis of the foramen magnum of dogs from the iron age. Anat Histol Embryol, 37: 359-361.

11. Janeczek M, Chroszcz A, Pospieszny N (2010) The occipital dysplasia in the papillion dog. EJPAU, 13: 6 .

12. Kahvecioglu KO, Onar V, Alpak H, Pazvant G (2000) The morphometry of foramen magnum in rabbits and its correlation with craniometric measurements. Folia Vet, 44: 62-69.

13. Mouhoub-sayah C, Robin JP, Malan A, Pevet P, Saboureau M (2008) Patterns of body temperature change in algerian hedgehog (Atelerix algirus) during autumn and winter. In: Lovegroove BGM ed. Hypometabolism in animals: Hibernation, topor, and cryobiology. Interpack Books, Pietermaritzburg, pp. 307-316.

14. Olopade JO (2006) Morphometric analysis of the skull of three breeds of goats in Nigeria. Ph.D. Thesis, Department of Veterinary Anatomy, University of Ibadan.

15. Olude MA, Olopade JO, Fatola IO, Onwuka SK (2009) Some aspect of the neurocraniometry of the African giant rat (Cricetomys gambianus waterhouse). Folia Morphol, 68: 224-227.

16. Onar V, Mutus R, Kahvecioglu KO (1997) Morphometric analysis of the foramen magnum in German shepherd dogs (Alsatians). Ann Anat, 179: 563-568.
17. Pares-Casanova PM (2012) Basicranial Analysis in young bovines reveals a relation to breed and sex. Anat Histol Embryol, 42: 398-401.

18. Park C, Kang BT, Yoo J-H, Park H-M (2009) Syringomyelia in three small breed dogs secondary to Chiari-like malformation: clinical and diagnostic findings. J Vet Sci, 10: 365-367.

19. Palmer AC, Blakemore WF, Franklin RJ, Frost LM, Gough RE, Lewis JC, Macdougall DF, O'Leary MT, Stocker LR (1998) Paralysis is hedgehogs (Erinaceus europaeus) associated with demyelination. Vet Rec, 153: 550-552

20. Parker AJ, Park RD (1974) Occipital dysplasia in the dogs. J Am Animal Hospital Assoc, 10: 520-525.

21. Richards GD, Jabbour RS (2011) Foramen magnum ontogeny in homo sapiens: a functional matrix perspective. Anat Record, 294: 199-216.

22. Rusbridge C, Knowler SP (2006) Coexistance of occipital dysplasia and occipital hypoplasia/syringomyelia in the cavalier king Charles spaniel. J Small Anim Pract, 47: 603-606.

23. Rusbridge C, Knowler SP, Pieterse L, McFadyen AK (2009) Chiari-like malformation in the griffon bruxellois. J Small Anim Pract, 50: 386-393.

24. Simoens P, Poels P, Lauwers H (1994) Morphometric analysis of the foramen magnum in a Pekingese dogs. Am J Vet Res, 55: 34-39.

25. Tubbs RS, Griessenauer CJ, Loukas M (2010) Morphometric analysis of foramen magnum: an anatomic study. Neurosurgery, 66: 385-388.

26. Ukoha U, Egwu O, Okafor I, Anyabolu A, Ndukwe G, Okpala I (2011) Sexual dimorphism in the foramen magnum of nigerian adult. Int J Biomed Resources, 2: 878-881.

27. Wasowicz M, Kupczyska M, Wieladek A, Barszcz K (2009) Morphometric analysis of occipital bone in the domestic cat in comparison with selected skull size parameters and with special regard to skull morphotype. Polish J Vet Science, 12: 251-258.

28. Watson AG, De Lahunta A, Evans HE (1989) Dorsal notch of foramen magnum due to incomplete ossification of supraoccipital bone in dogs. J Small Anim. Pract, 30: 666-673.

29. Wolfe KC, Poma R. (2010) Syringomyelia in the Cavalier King Charles Spaniel (CKCS) dog. Canadian Vet J, 51: 95-102.

30. Wright JA (1979) A studies of the radiographic anatomy of the foramen magnum in dogs. J Small Anim Pract, 20: 501-508.

31. Yahaya A, Olopade JO, Kwari HD (2013) Morphological analysis and osteometry of the foramen magnum of the one-humped camel (Camelus dromedarius). Anat Histol Embryol, 42: 155-159. 